\title{
Kopf-Hals-Radiologen aus ganz Europa zu Gast in Leipzig
}

\section{Kongresspräsidentin Sabrina Kösling begrüßte rund 300 Experten aus dem In- und Ausland}

Vom 13. bis 15. September fand in Leipzig der 25. Congress und Refresher Course der European Society of Head and Neck Radiology (ESHNR) statt. Die wissenschaft- liche Geamtleitung der Tagung oblag der Vorsitzenden der AG Kopf-Hals-Diagnostik in der Deutschen Röntgengesellschaft, Prof. Dr. Sabrina Kösling (Universitätskli- nikum Halle). Über 300 Experten aus Radiologie und angrenzenden klinischen Disziplinen waren der Einladung von Prof. Kösling gefolgt, um sich im Rahmen von 76 Vorträgen und Refresherkursen sowie 54 wissenschaftlichen Postern über die Entwicklungen der Kopf-Hals-Radiologie auszutauschen. Besonders zufrieden zeigte sich Prof. Kösling über die rege Teilnahme von außereuropäischen Gästen: „Mit Kolleginnen und Kollegen aus 38 Nationen war die diesjährige ESHNR-Tagung eine internationale und multikulturelle 
Veranstaltung. Ich freue mich, dass Kollegen aller Kontinente an unserem Kongress teilgenommen haben." Ausrichter und Schirmherr des Kongresses war die Deutsche Röntgengesellschaft e.V. Die 26. Jah- restagung wird vom 03.-05.Oktober 2013 in Izmir/ Türkei stattfinden.

Die Liste mit Preisträgern und der Fotogalerie finden Sie auf www.eshnr2012.org

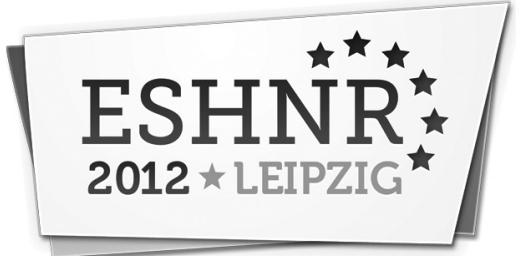

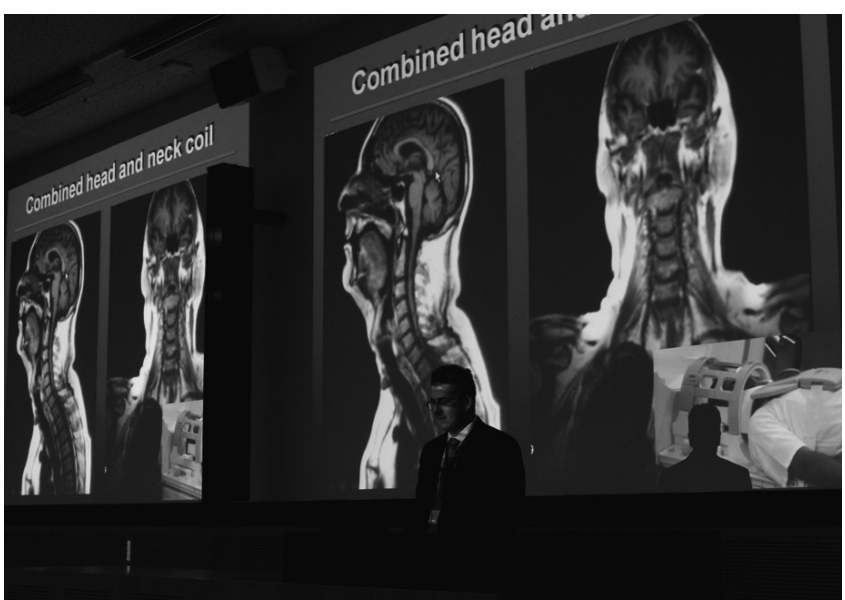
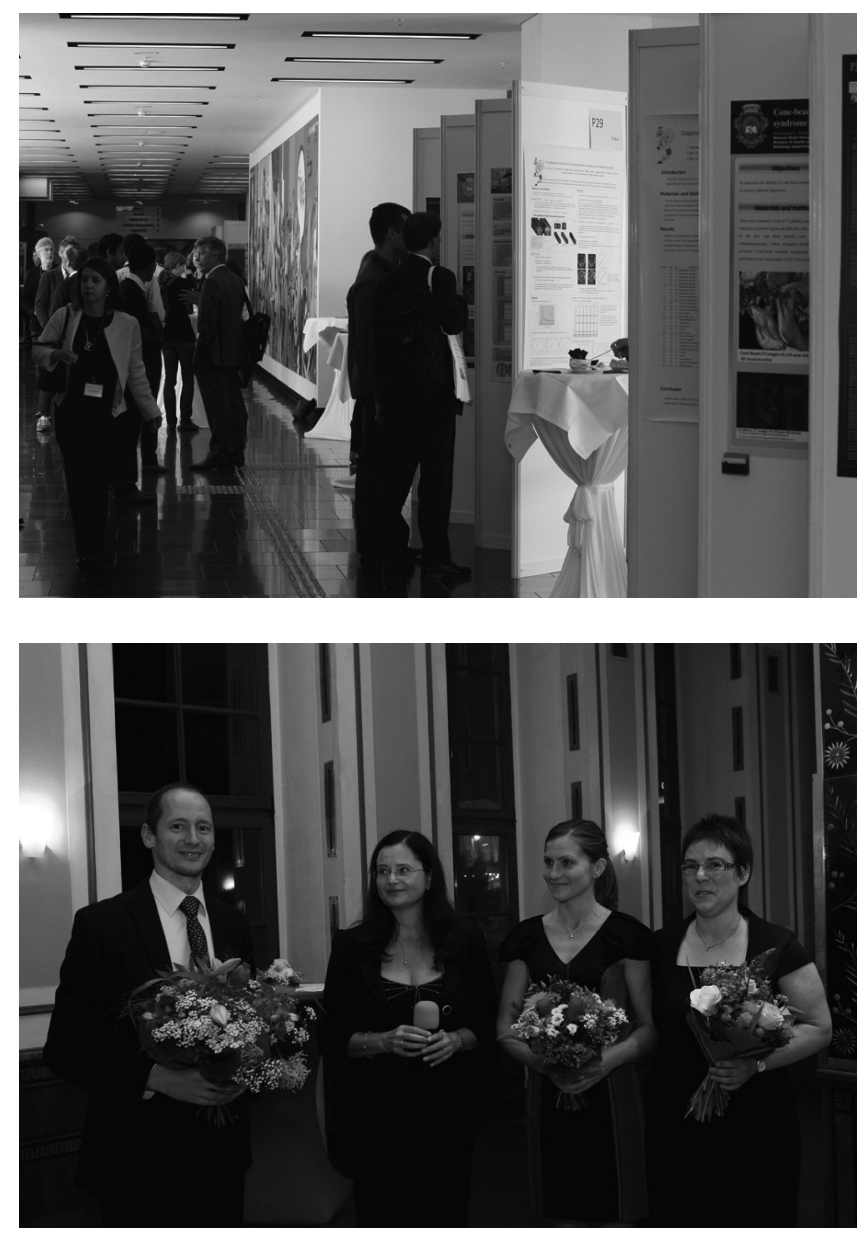
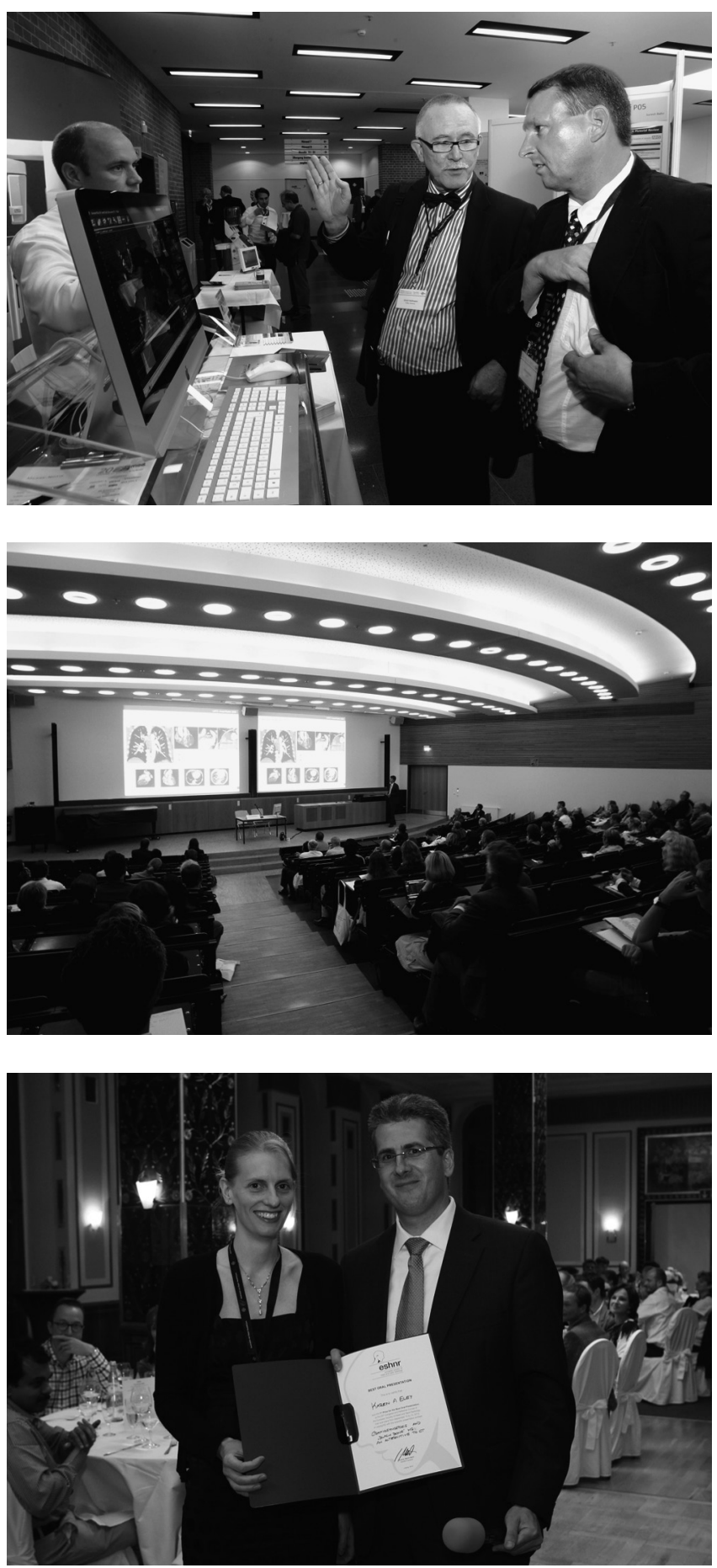